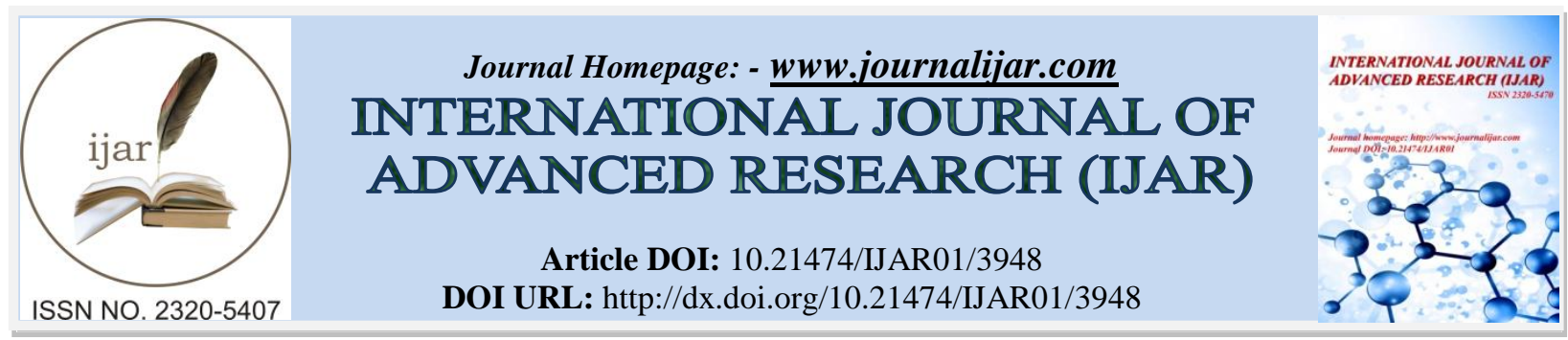

RESEARCH ARTICLE

\title{
UNIVERSITY FACULTY OPINION ON OPEN ACCESS PUBLISHING: A CASE STUDY OF FACULTY OF LIFE SCIENCES, ALIGARH MUSLIM UNIVERSITY, ALIGARH.
}

Shazia Khan ${ }^{1}$ and Zeba Khanam ${ }^{2}$.

1. Post Doctoral fellow, DLIS, AMU, Aligarh.

2. Senior Research Fellow, DLIS, AMU, Aligarh.

\section{Manuscript Info}

Manuscript History

Received: 16 February 2017

Final Accepted: 18 March 2017

Published: April 2017

\begin{abstract}
Open Access, a way for liberated availability of scholarly content through the Internet and an emerging concept for far ranging and unrestricted access to scholarly literature. OA journals and OA repositories (Institutional/Disciplinary Repositories) are the two main approaches of Open Access publishing. However, this mode of scholarly communication is not widely exploited in developing countries. This paper discusses the factors that influence the adoption of Open Access for scholarly communication and awareness, opinion and attitude of Faculty members of the Faculty of Life Sciences, AMU Aligarh. The sample population of 30 faculty members out of total 69 from the Faculty of Life Sciences, AMU Aligarh was taken to conduct the study. It was evident from the findings that the majority of Faculty members were aware of Open Access. However, most of the researchers preferred OA journals to publish but they reflect their interest in deposition into Institutional repositories. The current poor research conditions, non awareness of copyright issues, inadequate online publishing skills, and the slow Internet connectivity are the major barriers that deterred researchers to publish the research findings through Open Access means.
\end{abstract}

Copy Right, IJAR, 2017,. All rights reserved.

\section{Introduction:-}

"Open Access" (OA) and "Institutional Repositories" (IRs) have been buzz words in library literature for last decade. In 2001, the Budapest Open Access Initiative identified two ways for achieving OA goals. They are "Gold" OA (or author pays model) achieved by publishing in a peer-reviewed, scholarly OA journal in which articles are available in the public domain free of cost without any permission barrier and "Green" OA (or self-archiving) attained by publishing in any peer-reviewed journal (whether the availability is free or not) and then depositing a peer-reviewed version or preprint of the article in an OA repository. The Berlin Declaration of Open Access (2003), defines Open Access as "a mode of scholarly communication through which the "author(s) and right holder(s) of scholarly work grant(s) to all users a free, irrevocable, worldwide right of access to, and a license to copy, use, distribute, transmit, and display the work publicly in any digital medium for any responsible purpose, subject to proper attribution of authorship". Peter Suber in his article concisely defined OA as journal articles or books that are "digital, online, free of charge, and free of most copyright and licensing restrictions" (Suber, 2004). OA repositories can include articles that were published in gold OA journals or closed-access journals. Despite the promising potential for Open Access to improve scholarly communication, this mode of publishing is not yet wide spread in 
developing countries when compared to developed countries (Moller, 2006; Wang and Su, 2006; Directory of Open Access Repositories (DOAR), 2016).

The evolution of Open Access in India was started from Indian Academy of Science. The National Knowledge Commission of India (NKC) strongly recommends that peer-reviewed published research papers resulting from publicly funded research in India must be made available through Open Access channels (Das, 2008). Nowadays, the OA concept is evolving in India at higher rate and scholars are giving privilege to this model. The present study discussed the awareness, attitude and opinion of the Faculty members regarding Open Access mode of publishing.

\section{Literature Review:-}

An examination of the literature exposed that several surveys from across the globe on faculty attitudes and perceptions towards OA and IRs share similar findings, regardless of whether the survey was administered to faculty in a large research institution or a small liberal arts college; or what subjects the faculty were associated in, ranging from business to engineering, to science, to the humanities and social sciences. In this direction, Van Westrienen and Lynch's (2005) discusses the European survey notes low faculty participation in IRs due to confusion and uncertainty about intellectual property issues, as well as the perception of Open Access content being of low quality. In addition, Mischo and Schlembach (2011) studied engineering faculty at the University of Illinois at UrbanaChampaign to better understand their OA practices and attitudes. The survey results show that engineering faculty published little in author-pays "Gold" journals and had few plans to do so in the future. Furthermore, Dutta and Paul (2014) shared the results of their survey among selected science and technology faculty members of the University of Calcutta in India. They reported that the faculty members' attitudes regarding IR were generally positive. However, their awareness was less than satisfactory. They further revealed that most of the aware respondents came to discover their IR through the Internet. The copyright issue was the most influential factor with regard to unwillingness to contribute. In consistent with, Prince and Saravanan (2015) analyses the awareness and perception of users in the higher educational institutions in kanyakumari district towards Open Access resources. The study reveals that the majority of the respondents were fully aware about Open Access resources and use for their academic activities. It is also found that the majority of the respondents was using Open Access resources for their course related work and satisfied its uses in their academic activity. Yang and Le (2015) conducted a study to understand TAMU faculty awareness of Open Access (OA) publishing; assess their attitudes towards and willingness to contribute to an Institutional Repository (IR). Survey results suggested that tenured faculty are more engaged and interested in OA publishing topics in general and tenure-track faculty are more willing to adopt new initiative such as Open Textbooks. Overall, the responding TAMU faculties are willing to consider publishing in OA publications, and almost half of them believe OA journal publications are acceptable for consideration of tenure and promotion in their departments. Despite their positive attitudes towards OA publishing, they are not so positive towards OA mandates. The survey also revealed there is a low awareness level of the IR, as well as of newer OA trends and resources.

\section{Objectives:-}

1. To find out the awareness of Faculty Members about Open Access Publishing.

2. To find out the opinion of Faculty Members whether Open Access publishing is helpful for research productivity.

3. To find out factors that facilitates adoption of Open Access by Faculty Members.

4. To find out the Purpose for usage of Open Access Publishing

5. To determine the perception of Faculty Members towards the Open Access Resources

6. To find out the Problems while using OA publishing.

\section{Methodology:-}

The present study adopted the survey method for data gathering. The total population of the study consists of 69 faculty members of Life Sciences, Aligarh Muslim University (AMU), Aligarh. A self-administered questionnaire was randomly distributed to 60 faculty members of the Faculty of Life Sciences, AMU, Aligarh, selected through stratified random sampling ranging from the ranks of Assistant Professors to professors at Faculty of Life Sciences, AMU Aligarh. The stratified random sampling ensured obtaining the desired representation from the various subgroups on the basis of rank, age and higher degree of qualification of the Faculty Members. 
Of the 60 copies of the questionnaire were administered, 37 copies were returned and 7 questionnaires were not completely filled so they were rejected. Total 30 questionnaires were taken for analysis. Data analysis was done using frequency count and simple percentage method through MS excel.

Data Analysis and Interpretation:-

A total of 30 Faculty Members from Faculty of Life Sciences, AMU, Aligarh were participated in research.

\section{Profile of Faculty Members:-}

Rank:-

It is revealed from table 1 that close to a half (47\%) of the Faculty Members were Professors, followed by Assistant professors (37\%) and Associate Professors (17\%). It is clear that majority of the respondents were of Professor rank.

Table 1:- Distribution of Faculty Members by Rank.

\begin{tabular}{|c|c|c|}
\hline Distribution of Faculty Members by rank & Frequency & Percentage \\
\hline Professor & 14 & $47 \%$ \\
\hline Associate Professor & 5 & $17 \%$ \\
\hline Assistant Professor & 11 & $37 \%$ \\
\hline Total & $\mathbf{3 0}$ & $\mathbf{1 0 0 \%}$ \\
\hline
\end{tabular}

\section{Qualification:-}

In terms of the highest academic qualifications attained by the Faculty Members, 23 (77\%) were holders of PhD degrees while the remaining 7 (23\%) had Masters Degrees (Table 2). Fig 1 revealed that the majority of the respondents (76\% $\mathrm{PhD}$ and $78 \%$ Post Graduate) think that Open Access mode of Publishing is helpful for research productivity, while a few showed a negative perception for this view.

Table 2:- Distribution of Faculty Members by Qualification.

\begin{tabular}{|c|c|c|}
\hline Qualification & Frequency & Percentage \\
\hline PhD & 23 & $77 \%$ \\
\hline Masters/Post Graduate & 7 & $23 \%$ \\
\hline Total & $\mathbf{3 0}$ & $\mathbf{1 0 0 \%}$ \\
\hline
\end{tabular}

Fig 1: Do You think that Open Access Publishing is Helpful for Research Productivity

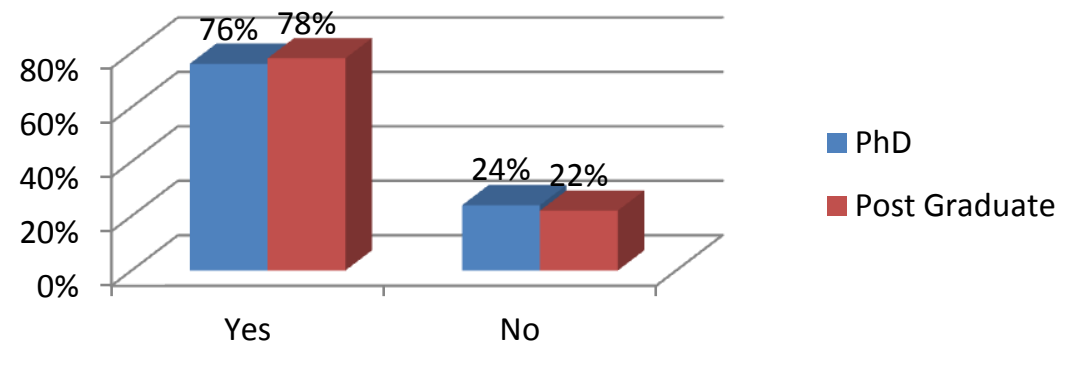

Age:-

With respect to age, 9 (30\%) were aged between 31-40 years; 10 (33\%) between $41-50$ years; 7 (23\%) between 5160 years; and 4 (13\%) were above sixty years. This shows that younger people are more tending to use Open Access mode of publishing. Fig 2 revealed that that the majority of the respondents (80per cent) between the ages of 41 and 50 followed by faculty members (75 percent) above 60 age thinks that Open Access mode of publishing is helpful for increasing research productivity while the close to half of those above the age of 51 (43 per cent) showed a negative opinion about the view. 
Table 3:- Distribution of Faculty Members by Age.

\begin{tabular}{|c|c|c|}
\hline Age(Years) & Frequency & \multicolumn{2}{c|}{ Percentage } \\
\hline $31-40$ & 9 & $33 \%$ \\
\hline $41-50$ & 10 & $23 \%$ \\
\hline $51-60$ & 7 & $13 \%$ \\
\hline Above 60 & 4 & $\mathbf{1 0 0 \%}$ \\
\hline Total & $\mathbf{3 0}$ & \multicolumn{2}{c|}{} \\
\hline
\end{tabular}

Fig 2: Do You think that Open Access Publishing is helpful for Research Productivity

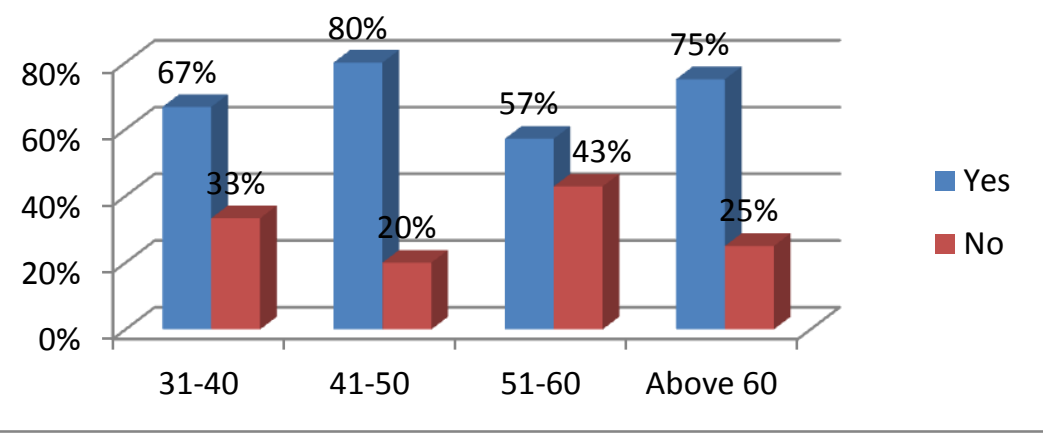

Awareness about Open Access publishing:-

As revealed from the fig 3, majority of the Faculty Members (83\%) were aware of Open Access Publishing. This means that for a good number, the Open Access concept was quite familiar and hence they were in a position to have an opinion about it.

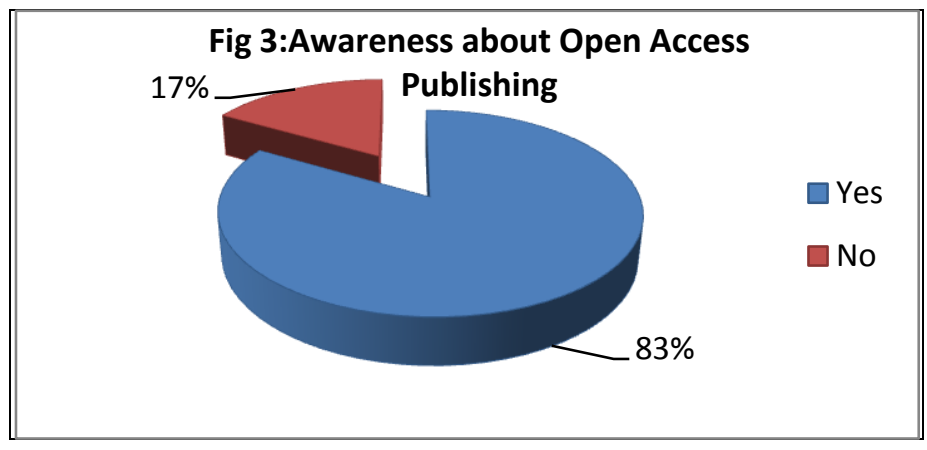

Purpose of use of Open Access mode (multiple answers required):-

The findings from this study (Table 4) indicate that majority (30\%) of the Faculty Members use Open Access mode to increase their visibility, followed by (29\%) who used to access the literature, while $21 \%$ disseminated their research findings and $20 \%$ for publishing their research output. The findings of the study revealed that the large number of researchers consider Open Access mode of publishing would increase the visibility of their research that further increases the citation rate.

Table 4:- Purpose of use of Open Access mode

\begin{tabular}{|c|c|c|c|}
\hline S.No. & Purpose & Frequency & Percentage \\
\hline 1 & To access literature & 25 & $29 \%$ \\
\hline 2 & For Publishing their Research output & 17 & $20 \%$ \\
\hline 3 & For increasing their Visibility & 26 & $30 \%$ \\
\hline 4 & For disseminating their research findings & 18 & $21 \%$ \\
\hline & Total & $\mathbf{8 6}$ & $\mathbf{1 0 0 \%}$ \\
\hline
\end{tabular}


Which route of Open Access publishing they prefer?

Table 5 showed that out of the total respondents (17) 57\% prefer Open Access Journals to publish their article in Open Access mode. Although a large number of faculty members prefer OA journals to publish their articles but a great majority $26(87 \%)$ of the faculty members think that Institutional Repositories raises the prestige of the institution (fig 4).

Table 5:- Preference regarding route of OA publishing

\begin{tabular}{|c|c|c|c|}
\hline S.No. & Route for publishing & Frequency & Percentage \\
\hline 1 & Open Access Journals & 17 & $57 \%$ \\
\hline 2 & Institutional Repositories & 7 & $23 \%$ \\
\hline 3 & Disciplinary Repositories & 6 & $20 \%$ \\
\hline & Total & $\mathbf{3 0}$ & $\mathbf{1 0 0 \%}$ \\
\hline
\end{tabular}

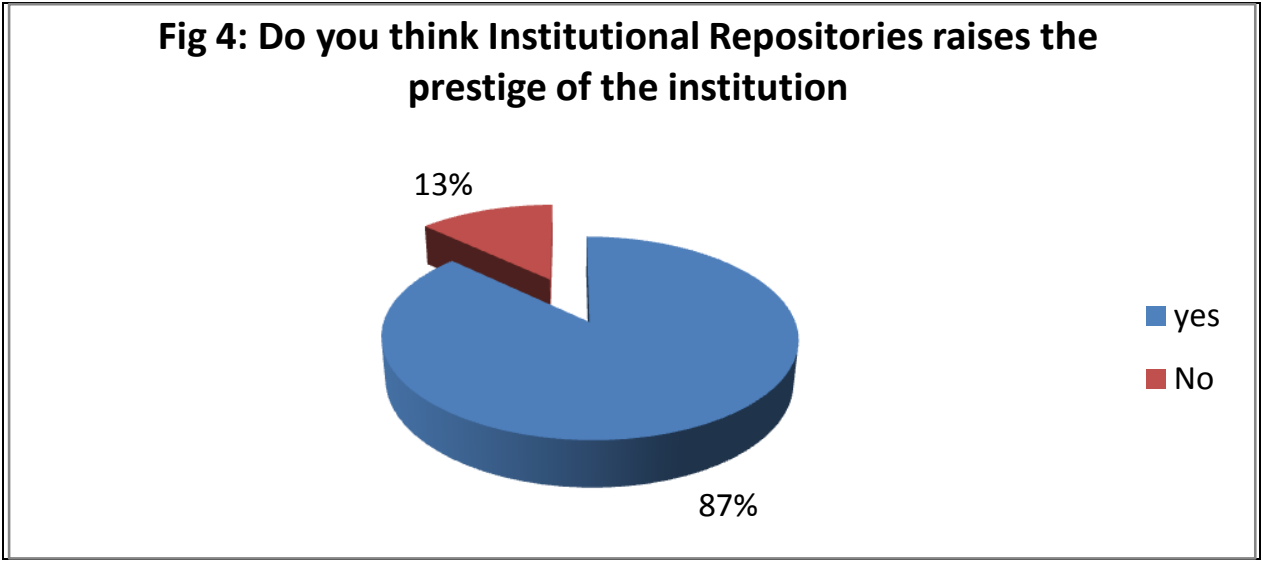

Faculty Members' Attitude and Opinion on Open Access Publishing:-

Table 5:- Attitude and Opinion of Faculty Members on Open Access Publishing.

\begin{tabular}{|c|c|c|c|c|c|c|}
\hline S.No. & Statements & SD & $\mathbf{D}$ & $\mathbf{N}$ & $\mathbf{A}$ & SA \\
\hline a) & Publications are original and represent high quality research & $13 \%$ & $17 \%$ & $13 \%$ & $27 \%$ & $30 \%$ \\
\hline b) & $\begin{array}{l}\text { It is easy to access Open Access scholarly content from the } \\
\text { Internet }\end{array}$ & $13 \%$ & $13 \%$ & $7 \%$ & $30 \%$ & $37 \%$ \\
\hline c) & $\begin{array}{l}\text { I have the necessary knowledge to publish my work in Open } \\
\text { Access outlets }\end{array}$ & $17 \%$ & $20 \%$ & $17 \%$ & $20 \%$ & $27 \%$ \\
\hline d) & $\begin{array}{l}\text { My institution recognizes Open Access publications for my } \\
\text { career development }\end{array}$ & $7 \%$ & $13 \%$ & $20 \%$ & $27 \%$ & $33 \%$ \\
\hline e) & I feel confident searching information on the Internet & $3 \%$ & $7 \%$ & $7 \%$ & $33 \%$ & $50 \%$ \\
\hline f) & I feel confident publishing research output on the Internet & $7 \%$ & $13 \%$ & $17 \%$ & $30 \%$ & $33 \%$ \\
\hline g) & $\begin{array}{l}\text { Open Access outlets increase research impact by researchers' } \\
\text { works being highly cited }\end{array}$ & $3 \%$ & $3 \%$ & $3 \%$ & $30 \%$ & $60 \%$ \\
\hline h) & $\begin{array}{l}\text { Open Access enables researchers from developing countries to } \\
\text { access literature more easily }\end{array}$ & $0 \%$ & $0 \%$ & $0 \%$ & $33 \%$ & $67 \%$ \\
\hline i) & $\begin{array}{l}\text { Publishing in Open Access outlets exposes scholarly } \\
\text { work to a large potential readership }\end{array}$ & $0 \%$ & $0 \%$ & $7 \%$ & $27 \%$ & $67 \%$ \\
\hline
\end{tabular}

Publications are original and represent high quality research:-

Thirty percent Faculty Members were strongly agree and twenty seven percent were agree with the statement, while seventeen percent were disagree with this view point.

It is easy to access Open Access scholarly content from the Internet:-

Out of the total Faculty Members, thirty seven percent and thirty percent were strongly agree and agree respectively with this statement whereas only thirteen percent were disagreeing with it. 
I have the necessary knowledge to publish my work in Open Access outlets:-

There was a partial response regarding the above view. Twenty seven percent fully supported the viewpoint whereas twenty percent were disagreeing with it.

My institution recognizes Open Access publications for my career development:-

Majority of the Faculty Members (33\%) were strongly agreed, 20\% agree while 7\% of the Faculty Members were strongly disagreeing with the above fact.

I feel confident searching information on the Internet:-

Majority (50\%) of the Faculty Members were strongly agreed with the viewpoint while only $3 \%$ of the Faculty Members were disagreeing with it.

I feel confident publishing research output on the Internet:-

$33 \%$ and 30\% of the Faculty Members feel confident publishing research output on the internet whereas $7 \%$ were strongly disagree with it.

Open Access outlets increase research impact by researchers' works being highly cited:-

Majority of the Faculty Members (60\%) were strongly agreed with the fact on the other hand only 3\% were strongly disagreeing.

Open Access enables researchers from developing countries to access literature more easily:-

Majority of Faculty Members (67\%) were agreeing with this view point while no one was disagreeing with this view.

Publishing in Open Access outlets exposes scholarly work to a large potential readership:-

Majority of Faculty Members (67\%) were agreeing with this view point while 7\% had no opinion on this view.

Barriers faced while using Open Access Publishing (multiple answers required):-

As shown in the table 6 below top six barriers related to the use of Open Access Publishing by Faculty Members. 25\% Faculty Members considered copyright is the major issue while publishing through OA mode followed by fear of authenticity (20\%) and lack of online publishing skills(20\%).A few of them considered slow internet connectivity (17\%) and erratic power supply (15\%) as a barrier. A negligible number 5 (4\%) thought Lack of awareness as the issue regarding the use of Open Access publishing.

Table 6:- Problems faced while using Open Access Publishing

\begin{tabular}{|c|c|c|c|}
\hline S.No. & Problems & Frequency & Percentage \\
\hline 1 & Lack of awareness & 5 & $4 \%$ \\
\hline 2 & Copyright & 30 & $25 \%$ \\
\hline 3 & Fear of Authenticity & 24 & $20 \%$ \\
\hline 4 & Slow Internet Connectivity & 20 & $17 \%$ \\
\hline 5 & Erratic Power Supply & 18 & $15 \%$ \\
\hline 6 & Lack of online Publishing skills & 24 & $20 \%$ \\
\hline & Total & $\mathbf{1 2 1}$ & $\mathbf{1 0 0 \%}$ \\
\hline
\end{tabular}

\section{Findings and Summary:-}

1. Majority of the Faculty members of the faculty of Life Sciences, AMU, Aligarh are aware of Open Access publishing.

2. Majority of the Respondents that have the positive perception regarding the view that Open Access Mode of Publishing is helpful to increase the research productivity are the holders of $\mathrm{PhD}$ degree.

3. A good number of respondents thought that to publish via Open Access mode will increase citation rate that further increases their productivity.

4. Majority of the faculty members of the faculty of Life Sciences, AMU, Aligarh feel confident while publishing research output on the internet via Open Access mode of publishing.

5. Majority of the faculty members of the faculty of Life Sciences, AMU, Aligarh shows greater interest in Open Access journals and wanted to publish their work in OA journals. 
6. Majority of the faculty members of the faculty of Life Sciences, AMU, Aligarh thought that Institutional Repositories would increases the prestige of the institution.

7. Majority of Faculty Members were agreed for the view that Open Access enables researchers from developing countries to access literature more easily.

8. Although the study revealed that majority of the respondents showed their interest in OA mode of publishing but some barriers were faced by them regarding copyright, lack of skills publishing online and they also have fear regarding the authenticity of OA publishing.

\section{Conclusion:-}

The majority of countering faculty members of the Faculty of Life Sciences, AMU Aligarh is aware of OA journals and indicated their willingness to publish via OA mode. Although the faculty members considered that Institutional Repositories would increases the prestige of the institution but they feel comfortable to publish in OA journal publication. In line with previous studies, copyright concerns, as well as the fear of authenticity were the significant barriers noted. The present study concluded that institutional policy on scholarly communication should be amended to integrate the use of Open Access publishing. It appears that if more information were provided regarding the OA mode of publishing via conferences, seminars, trainings and workshops, a majority of scholars in India would be interested in contributing their work. It also suggests that time to time workshops should be conducted for the scholars for improving and simplifying the deposit process, might be vital for increasing the IR participation rate. Moreover, universities should accelerate the establishment of institutional repositories and the enhancement of Internet speed at universities through subscription to more bandwidth so as to meet the demand from the learned community.

\section{References:-}

1. Berlin Declaration of Open Access. (2003). Retrieved July 14, 2015, from http://www.zim.mfg.de/openaccessberlin/berlin_declaration.html

2. Budapest Open Access Initiative (2002). Retrieved July 27, 2010, from http://www.budapestopenaccessinitiative.org/read

3. Das, A. K. (2008). Open Access to knowledge and information scholarly literature and digital library initiatives the South Asian scenario. New Delhi: UNESCO

4. Directory of Open Access Repositories (DOAR). (2016). Retrieved March 12, 2016 from: http://www.opendoar.org (Accessed 25 April 2020).

5. Dutta, G. \& Paul, D. (2014). Awareness on institutional repositories-related issues by faculty of university of Calcutta. Journal of Library \& Information Technology, 34(4), 293-297. DOI: http://dx.doi.org/10.14429/djlit.34.5138

6. Mischo, W. H. \& Schlembach, M. C. (2011). Open Access issues and engineering faculty attitudes and practices. Journal of Library Administration, 51(5-6), 432-454. DOI: http://dx.doi.org/10.1080/01930826.2011.589349

7. Moller, A.M. (2006). The case of Open Access publishing, with special reference to Open Access journal and their prospects in South Africa. (Unpublished Dissertation, University of Western Cape, South Africa, MA.). Retrieved August 23, 2016, from http://eprints.rclis.org/archive/000518/01/MollerThesis.pdf

8. Prince, G. \& Sarvanan, P. (2015). A Study on Awareness and Perception towards Open Access Resources among the Users in the Higher Educational Institutions in Kanyakumari District. International Journal of Next Generation Library and Technologies, 1(3),1-9. Retrieved November 23, 2016, from http://www.ijnglt.com/files/Issue\%203/A\%20Study\%20on\%20Awareness\%20User\%20Perception.pdf

9. Suber, P. (2002). Soros/Open Access. Retrieved July 20, 2014, from http://www.soros.org/openaccess.

10. Van Westrienen, G. \& Lynch, C. A. (2005). Academic institutional repositories: Development status in 13 nations as of mid 2005. D-Lib Magazine, 11(9). DOI: http://dx.doi.org/10.1045/september2005-westrienen

11. Wang, X. \& Su, C. 2006. Open Access - philosophy, policy and practice: A comparative study. In World library and information congress: 72nd IFLA general conference and council,20-24 August 2006, (Seoul, Korea, 2006). Retrieved February 20, 2015, from http://elpub.scix.net/data/workshop/att/121elpub2007.content.pdf

12. Yang, Z. Y., \& Li, Y. (2015). University Faculty Awareness and Attitudes towards Open Access Publishing and the Institutional Repository: A Case Study. Journal of Librarianship and Scholarly Communication, 3(1), eP1210. http://dx.doi.org/10.7710/2162-3309.1210 